\title{
Use of Dynamites, Water-Gels and Emulsion Explosives in Sri Lankan Quarrying/Mining Practice
}

\author{
P. V. A. Hemalal, P. G. R. Dharmaratne and P. I. Kumarage
}

\begin{abstract}
In the Sri Lankan mining and quarrying industry, gelatine dynamite has been the widely used explosive for rock blasting purposes. In the recent past, it has been phased out and replaced by locally manufactured Water-gels(WG). So far, there had been only a very few tests conducted to assess the suitability and to evaluate the performance of this explosive with other available explosives. Complaints made by the users of Water-gels have been a cause of concern and prompted research to be conducted with the aim of evaluating the performance of Dynamites, Water-gels and Emulsion explosives with the measurement of major performance indicators in local mining and quarrying practice.
\end{abstract}

In this research, performance comparison of WG, Dynamite and Emulsion explosives with regard to rock breakage in underground tunnelling and in metal quarrying has been carried out. Comparison of fragmentation with the evaluation of particle size distribution in concrete block blasting using the three types of explosives has been one of the main tests. Gap sensitivity, density and the determination of velocity of detonation (VOD) has also been carried out.

Keywords: $\quad$ D'Autriche's Method, Gap Sensitivity, VOD, Explosives

\section{Introduction}

Water-gel(WG) was introduced to Sri Lanka in 2011 as a substitute for dynamite. So far there had been only a very few tests conducted to assess the suitability and to evaluate the performance of this explosive in contrast to other available explosives.

Water-gel currently produced in Sri Lanka has been introduced to the industry by the government. The complaints made by the users with regard to the performance of watergels have been a cause of concern.

In this research, performance of water-gel explosives currently in use has been evaluated with that of emulsions and dynamite, with a view to identifying their deficiencies and propose measures to overcome them with a view to optimize its usage in Sri Lankan mining practice.

Fragmentation ability of explosives has been compared using blasting in concrete blocks. Fragments were analysed using SPLIT software. Concrete blocks were used to obtain a homogenous material to obtain a better reproducibility of tests.

Underground tunnelling has been carried out both with WG and dynamite and tunnel advances has been compared with identical cut ole configurations.
Density measurements and gap sensitivity has been conducted to cross check the manufacturers' specifications on WG.

Measurement of VOD using D'Autriche's method was carried out for the first time in Sri Lanka for Dynamite, Water-gel and Emulsion explosives.

\section{Methodology}

\subsection{Test Blasting on Concrete Blocks}

Concrete blocks of $0.5 \mathrm{~m} \times 0.5 \mathrm{~m} \times 0.5 \mathrm{~m}$ in size having a $32 \mathrm{~mm}$ diameter centre hole of $30 \mathrm{~cm}$ deep were made to facilitate explosive charging(Figure 1). Blocks were cured under same conditions for 28 days. Average compressive strength of concrete measured by sample blocks was $40.6 \mathrm{~N} / \mathrm{mm}^{2}$.

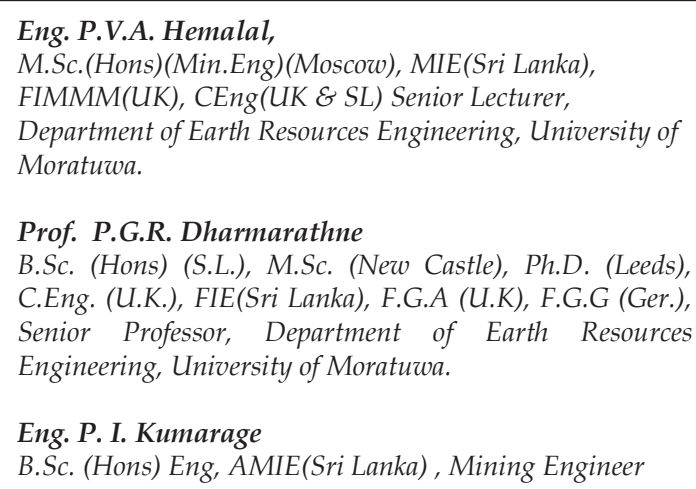




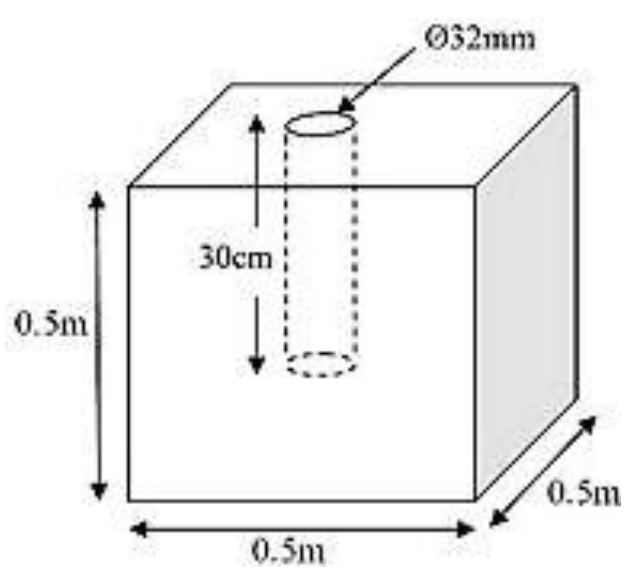

Figure 1 - Concrete block dimensions

Three explosive types namely, Water-gel (WG), Dynamite and Emulsion were charged in quantities of $25 \mathrm{~g}$ and $30 \mathrm{~g}$ to study the fragmentation level by each explosive. Quarry dust was used as stemming material and no ANFO was used.

After the blast, all fragments were collected, weighed, photographed, and digitally analysed using SPLIT software.

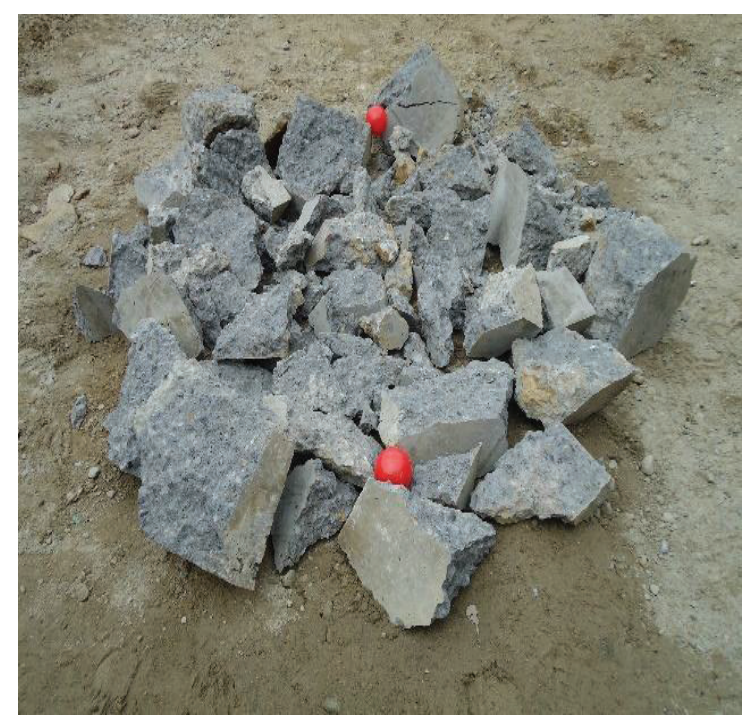

Figure 2 - Collected concrete fragments after the blast

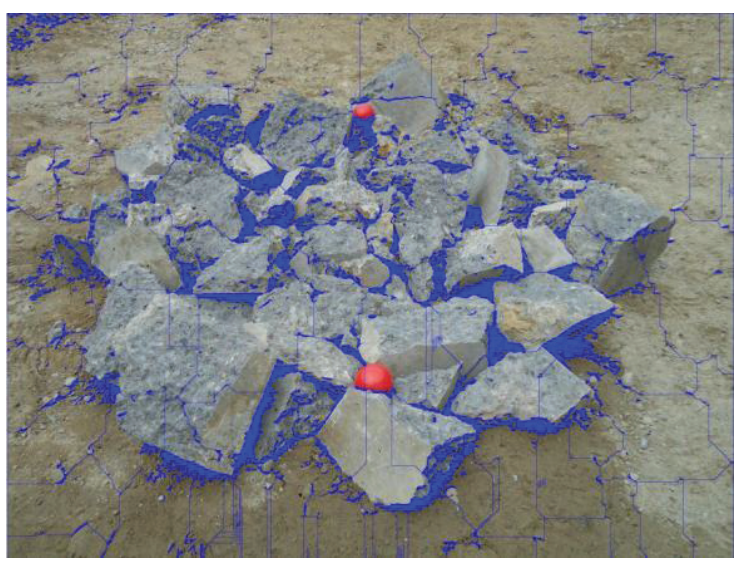

Figure 3 - Delineated image by the SPLIT software

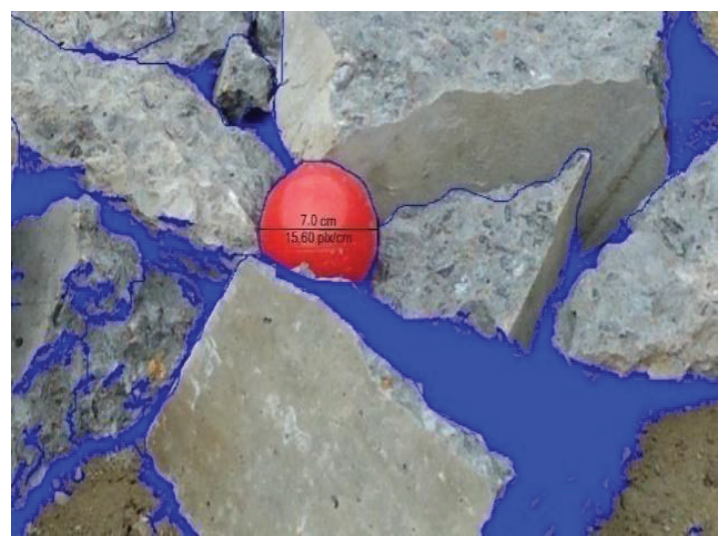

Figure 4 - Scaling with a reference object

Boundaries of collected fragments were identified by the software by delineating. The delineated lines have to be manually edited to eliminate minor errors using the facilities given in the software package itself. Scaling is the identification of the actual size of the fragments with the help of a given reference object in the image. (Figure 4).

After completing the image analysis, particle size distribution curve can be produced (Figure 5). These data have been exported to MSExcel for further analysis.

\subsection{Underground Test blast of Water-gel vs. Gelatin dynamite.}

There are no complete or successful comparisons on the use of different types of explosives in underground situations in local context. Therefore several test blasts were carried out in a tunnel at Bogala mines with identical cut-hole configurations, to evaluate the performance of explosives in underground rock blasting. 


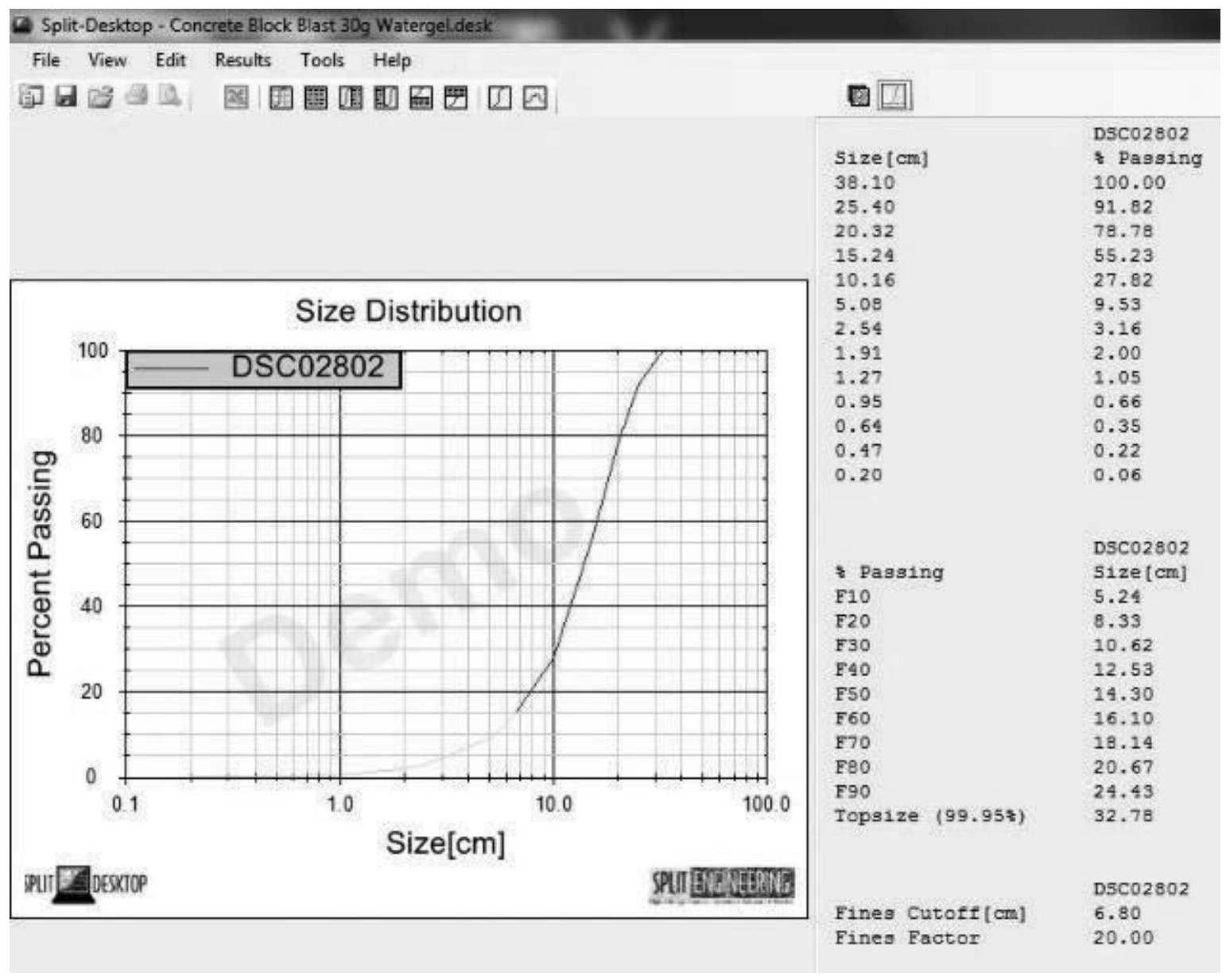

Figure 5 - Particle size distribution curve produced by the software

Cross-cut tunnel advance (as at June, 2012) of Bogala Graphite Mine, Aruggammana Graphit-Kropfmuhl (Lanka) Ltd Sri Lanka, in $191 \mathrm{~m}$ level was used for this study. Gelatine dynamite and locally-manufactured Watergels by Kelani Fireworks Company were used as explosives. Swedish-made millisecond and half second, number 08 detonators were used in every blast as initiators.

Adopted drill pattern consisted of 37 drillholes and is shown in Figure 6.

Figure 6 Reamer hole at the centre (hole No.1) having a diameter of $45 \mathrm{~mm}$ and charged drill holes of $35 \mathrm{~mm}$ diameter were drilled.

In Figure 6, hole Nos.1 to 9 make up cut-hole round of burn cut configuration. Centre hole (hole No.1) was left un-charged to facilitate as a free space for the rock to be blasted into. Hole No. 2 to 9, the remaining holes of the burn cut hole, were charged with $0.5 \mathrm{~kg}$ of Water-gel explosives each with no ANFO used.
Burn cut requires high explosives as the free space available is too small. All the remaining holes of the blasting round were charged with $0.375 \mathrm{~kg}$ of water-gel and $0.4 \mathrm{~kg}$ of ANFO for each hole. Since the cut hole is already blasted, it provides sufficient free space for the surrounding holes to blast into, and therefore less strength of explosives is sufficient.

Whole Burn Cut made up of hole No. 2 to 9 and other stopping holes (hole No. 10 to 21) were initiated with millisecond delays while perimeter holes (hole No.22 to 37) were charged with half second delays.

Tunnel face was charged with one explosive type and the advance was measured. Test was repeated for other explosive types as well. 


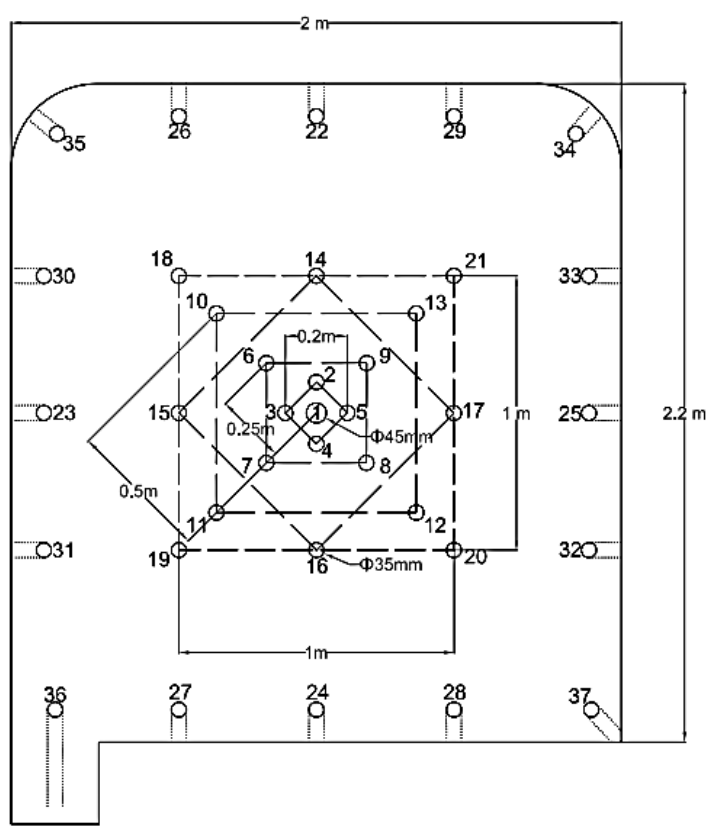

Figure 6 - Drilling pattern

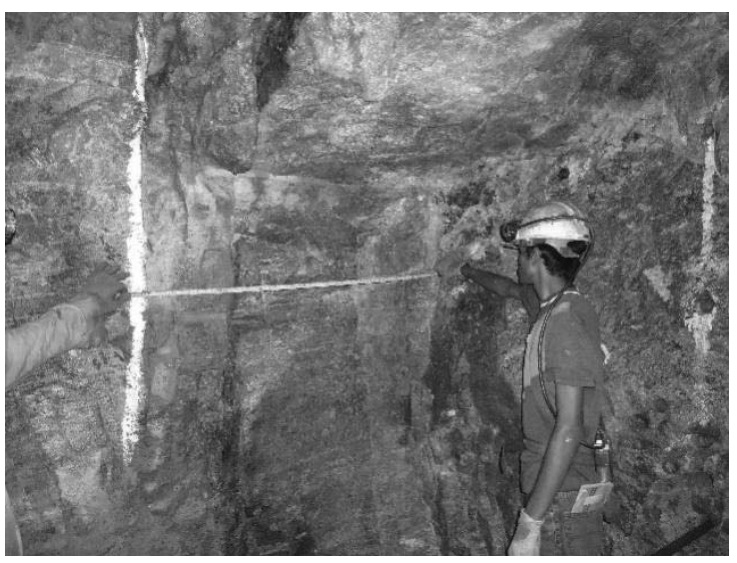

Figure 7 - Measuring the tunnel advance after the blast using a reference mark on tunnel wall.

\subsection{Density measurement.}

Density measurements were carried out by weighing and measuring the volume by water displacement. A graph was produced with weight over volume with different observed values.

\subsection{Air Gap sensitivity.}

Placing two half cartridges with varying gap between them, one half inserted with an electric detonator of No.6 strength and directed towards the other half was blasted. The initial gap in air was taken as $2 \mathrm{~cm}$ as the specified gap of the locally made Water-gel explosive is $2 \mathrm{~cm}$. For Water-gel, this test was a cross check of the given specification.
The test determines the ability of an explosive to transmit detonation through air from one charge to another some distance away.

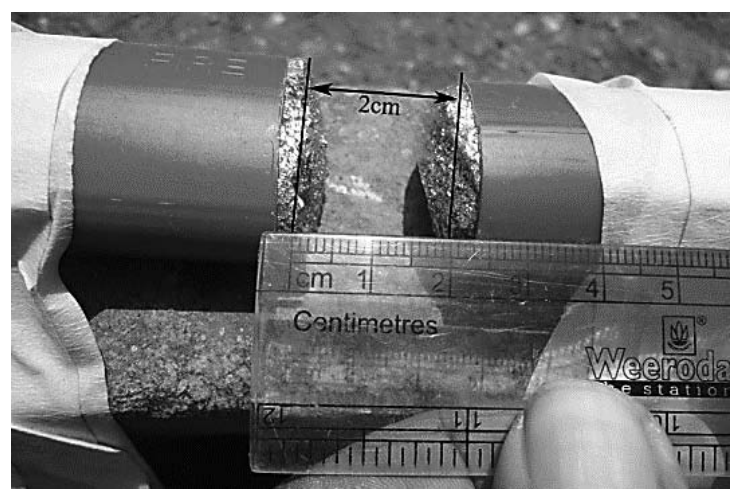

Figure 8 - Gap sensitivity arrangement on field

\subsection{VOD Measurement.}

Velocity of Detonation is to be measured using the D'Autriche's method.

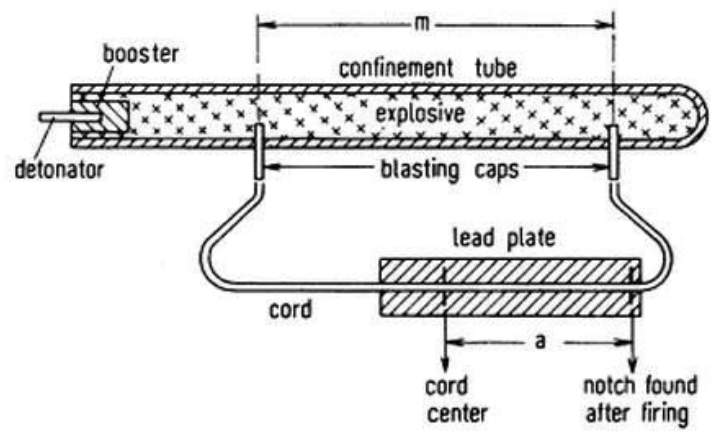

Figure 9 - Schematic arrangement for Dautriche method VOD measurement.

As shown in Figure 9 above, two blasting caps were inserted to the explosive column of the cartridge and the separation was measured (m). A loop was made with a detonating code with a known VOD. The middle part (centre) of the code was passed over a lead plate and taped in place. Once the explosive column was detonated, the two ends of the cord ignited successively and the two waves meet head-on on the lead plate, a distance off centred of the geometric centre of the code.

After blasting, VOD of the explosive canbe calculated from equation 1, knowing the Detonating cord separation (m), off-centre distance (a) and VOD of the Detonating cord, $\mathrm{D}(\mathrm{M} / \mathrm{s})$,

$\mathrm{VOD}=\mathrm{Dm} / 2 \mathrm{a}$ 


\section{Results \& Discussion}

\subsection{Results of Concrete Block Blasting}

Following Figure 12 shows the particle size distribution after blasting with $25 \mathrm{~g}$ of each type of explosives.

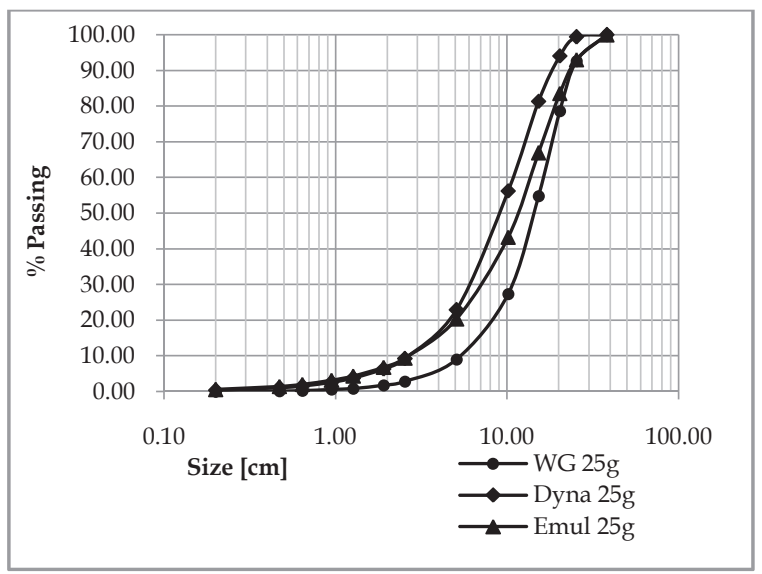

Figure 10 - Particle Size Distribution graph for $25 \mathrm{~g}$ charge of explosives in the block.

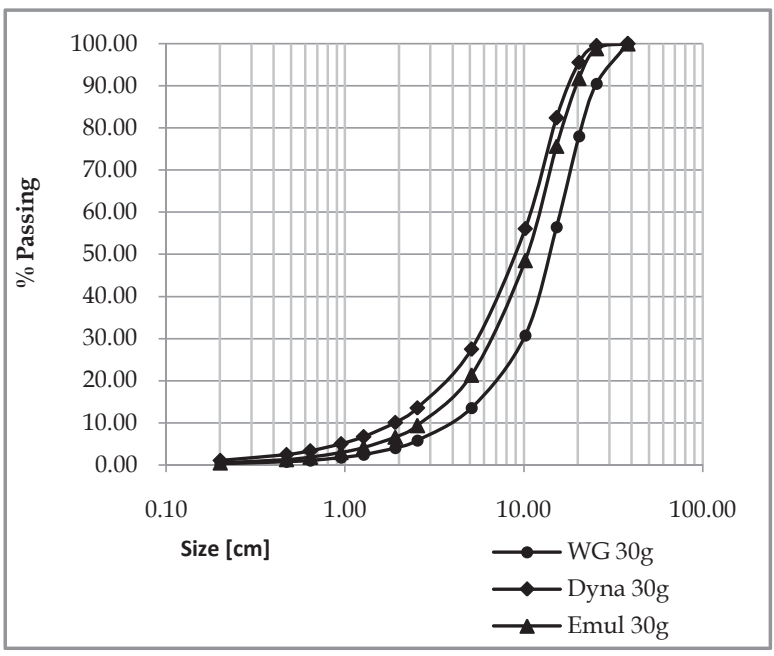

Figure 11 - Particle Size Distribution graph for $30 \mathrm{~g}$ charge of explosives in the block

Figure 11 shows the particle size distribution for $30 \mathrm{~g}$ of explosive charge.

From these graphs, it is clear that in both $30 \mathrm{~g}$ and 25g charge tests, all D10, D30, D50 and D60 values have increased from dynamite to water-gel. This clearly shows that fragmentation is best in dynamite second in emulsion and water-gels is the third.
3.2 Results of underground tunnel blasting.

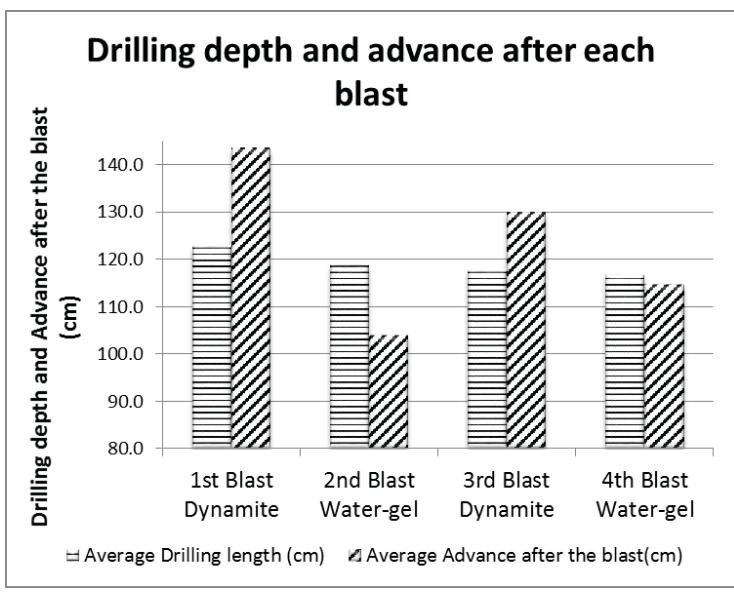

Figure 12 - Drilling depth and Advance after each blast

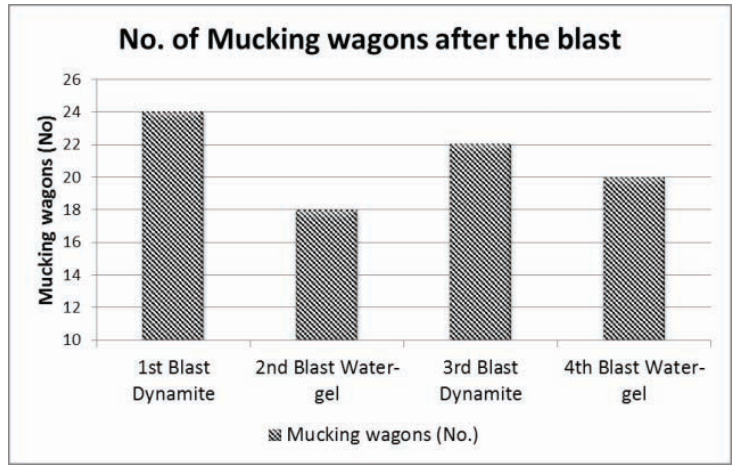

Figure 13 - Number of mucking wagons after the blast

Figure 12 illustrates the drilling depths and tunnel advances after the blast. It is clear that dynamite is capable of advances even beyond the drilling length. With Water-gel it always remains a part of the drilling length. Average advance with Dynamite is $113.7 \%$ of the drilling length, whereas it is $92.9 \%$ with Watergel.

Number of mucking wagons, which indicates the amount of rock blasted is also higher in dynamites than of water-gels (Figure 13).

Hence Tunnel advance using water-gels is less than that of dynamite for the same charge and same cut hole configurations.

\subsection{Results of density measurements.}

Figure 14 shows the mass and the respective volumes for water-gel. Hence the gradient of the regression line is mass/volume which is the density. 


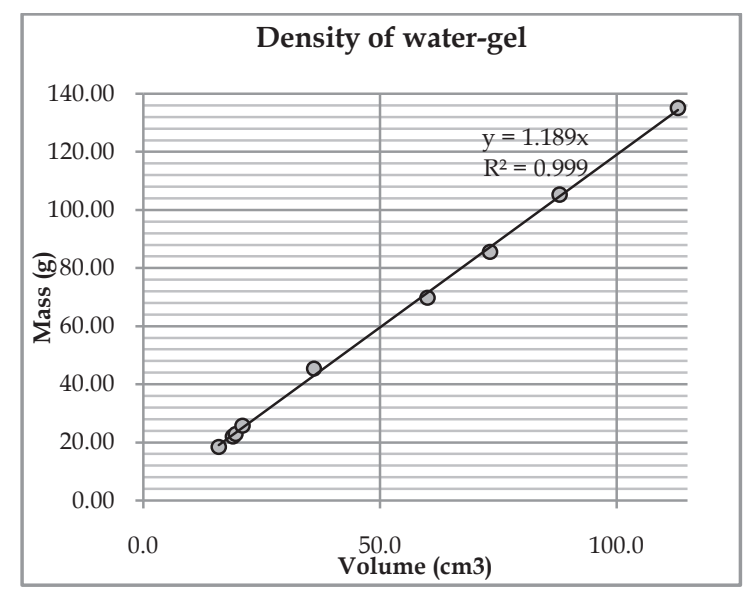

Figure 14 - Mass vs. Volume for WG

Average density of WG was $1.19 \mathrm{~g} / \mathrm{cc}$. In the same manner densities of Emulsion and Dynamite were $1.21 \mathrm{~g} / \mathrm{cc}$ and $1.29 \mathrm{~g} / \mathrm{cc}$ respectively.

Table 1- Average densities of explosives

\begin{tabular}{|l|l|}
\hline Explosive Type & Average Density $\mathbf{( g / c c}$ \\
\hline Water-gel & 1.19 \\
\hline Emulsion & 1.21 \\
\hline Dynamite & 1.29 \\
\hline
\end{tabular}

From the Table 1, it is clear that dynamite has the highest density equal to $1.29 \mathrm{~g} / \mathrm{cc}$.

Density of water-gel and emulsion lies close by with a gap of $0.02 \mathrm{~g} / \mathrm{cc}$, although emulsion has slightly a high density of $1.21 \mathrm{~g} / \mathrm{cc}$.

\subsection{Results of gap sensitivity for water-} gel.

After the blast, the immediate environment where the donor was placed was observed. The discolouration due to burning of the location of the receptor was a clear indication of the detonation of the receptor. Hence, it could be concluded that the receptor has got the detonation through air from the donor and, the test result was positive for an air gap of $2 \mathrm{~cm}$.

Followed by successful results of the first test it was decided to carry out one more trial increasing the air gap to $3 \mathrm{~cm}$. The result with this increased gap was also positive.

\subsection{Results of VOD measurements.}

Table 2 below presents the results of the D'Autriche'stest.
Table 2 - Resultant VOD values from D'Autriche's method

\begin{tabular}{|l|l|l|l|l|}
\hline $\begin{array}{l}\text { Explosive } \\
\text { Type }\end{array}$ & $\begin{array}{l}\text { Gap } \\
\text { between } \\
\text { DC } \\
\text { nodes } \\
(\mathbf{m m})\end{array}$ & $\begin{array}{l}\text { Off set } \\
\text { gap on } \\
\text { lead } \\
\text { plate } \\
(\mathbf{m m})\end{array}$ & $\begin{array}{l}\text { VOD } \\
\text { of DC } \\
(\mathbf{m} / \mathbf{s})\end{array}$ & $\begin{array}{l}\text { VOD } \\
(\mathbf{m} / \mathbf{s})\end{array}$ \\
\hline Water-gel & 100 & 84 & 6,750 & 4,018 \\
\hline Emulsion & 100 & 68 & 6,750 & 4,963 \\
\hline Dynamite & 100 & 60 & 6,750 & 5,625 \\
\hline
\end{tabular}

It is clear from Table 2 that dynamite has the highest VOD of $5,625 \mathrm{~m} / \mathrm{s}$ and Water-gel has the lowest of $4,018 \mathrm{~m} / \mathrm{s}$. VOD of emulsion is in between with a value of $4963 \mathrm{~m} / \mathrm{s}$.

\section{Conclusions}

In underground blasting water-gel is environmentally friendlier than dynamite. This is due to the absence of odour of Nitroglycerine emanating from the cartridge in the course of charging and post-blast toxic fumes causing headaches and dizziness in confined underground mining environments.

Gap sensitivity of Water-gel was found to be better than the expected value of $2 \mathrm{~cm}$. The results were positive even with a gap of $3 \mathrm{~cm}$.

Water-gel is a low energy explosive than dynamite and emulsion. Fragmentation of water-gel was found to be less than that of dynamite as demonstrated in surface concrete block blasting and underground muck pile analysis. The conclusion to be arrived is that detonation characterised by the low velocity of detonation creates a weak fracture system affecting the level of fragmentation of the rock.

Tunnel Advance with dynamite was better than with that of Water-gels. Although the explosive material cost per blasting round is less in Water-gel due to its low price, this advantage has been overrun due to the low rate of tunnel advancements and consequent additional blasting rounds required with water-gels.

It can be conjectured that Water-gel is dead pressed in underground shot hole tunnel blasting at Bogala mines due to the close proximity blast holes in the order of few centimeters in the cut hole configuration. Therefore, explosives residues were a frequent observation. 
Density of Water-gel lies within the range of the manufacturer, i.e. $1.16 \mathrm{~g} / \mathrm{cc}$ to $1.26 \mathrm{~g} / \mathrm{cc}$. and, it is $1.29 \mathrm{~g} / \mathrm{cc}$ and $1.21 \mathrm{~g} / \mathrm{cc}$ with dynamite and emulsion respectively. It is clear that density of Water-gel is lower than that of dynamite.

VOD was successfully measured by the D'Autriche's method for the first time in Sri Lanka. By referring to Table 2 it is clear that dynamite has the highest VOD and WG has the lowest.

\section{Acknowledgement}

Our gratitude goes to:

Messers. KDA Weerasinghe quarry, Kalutara; BogalaMines, Aruggammana, Limestone Quarry, Holcim Lanka Ltd., Aruwakkalu; Explosive controller, Deputy Controller and Assistant Controllers of explosives - Kalutara and all other organizations who assisted us in the course of field work.

Prof. Manoj Pradhan, Department of Mining, National Institute of Technology (NIT), Raipur, India is gratefully acknowledged for advices given on VOD testing of explosives.

\section{References}

1. Persson, P.-A., Holmberg, R., \& Lee, J. "Rock Blasting and Explosives Engineering", CRC Press (2001).

2. Jimeno, C. L., Jimeno, E. L., \& Carcedo, F. J. A. "Drilling and Blasting of Rocks". Taylor $\mathcal{E}$ Francis. (1995).

3. Meyer, R., Köhler, J., \& Homburg, A. "Explosives", Wiley-VCH. (2007).

4. Cooper, P. W. "Explosives Engineering", WileyVCH (1997). 